\title{
Molecularly imprinted polymers as the extracted sorbents of clenbuterol ahead of liquid chromatographic determination*
}

\author{
Sovichea LAY ${ }^{1}$, Hai-ning $\mathrm{YU}^{2}$, Bao-xiang $\mathrm{HU}^{3}$, Sheng-rong SHEN ${ }^{\dagger 1}$ \\ ('Department of Food Science and Nutrition, Zhejiang University, Hangzhou 310058, China) \\ $\left({ }^{2}\right.$ College of Pharmaceutical Science, Zhejiang University of Technology, Hangzhou 310032, China) \\ $\left({ }^{3}\right.$ Department of Chemical Engineering and Material Science, Zhejiang University of Technology, Hangzhou 310032, China) \\ †E-mail: shrshen@zju.edu.cn \\ Received Sept. 16, 2015; Revision accepted Jan. 25, 2016; Crosschecked May 12, 2016
}

\begin{abstract}
A pre-treatment methodology for clenbuterol hydrochloride (CLEN) isolation and enrichment in a complex matrix environment was developed through exploiting molecularly imprinted polymers (MIPs). CLEN-imprinted polymers were synthesized by the combined use of ally- $\beta$-cyclodextrin (ally- $\beta-C D$ ) and methacrylic acid (MAA), allyl- $\beta-C D$ and acrylonitrile (AN), and allyl- $\beta-C D$ and methyl methacrylate (MMA) as the binary functional monomers. MAA-linked allyl- $\beta-C D$ MIPs (M-MAA) were characterized by Fourier transform-infrared (FT-IR) spectroscopy and a scanning electron microscope (SEM). Based upon the results, M-MAA polymers generally proved to be an excellent selective extraction compared to its references: AN-linked allyl- $\beta$-CD MIPs (M-AN) and MMA-linked allyl- $\beta$-CD MIPs (M-MMA). M-MAA polymers were eventually chosen to run through a molecularly imprinted solid-phase extraction (MISPE) micro-column to enrich CLEN residues spiked in pig livers. A high recovery was achieved, ranging from $91.03 \%$ to $96.76 \%$ with relative standard deviation (RSD) $\leq 4.45 \%$.
\end{abstract}

Key words: Molecularly imprinted polymer (MIP), Molecularly imprinted solid-phase extraction (MISPE), Clenbuterol, Cyclodextrin

http://dx.doi.org/10.1631/jzus.B1500225

CLC number: S188

\section{Introduction}

Clenbuterol hydrochloride (CLEN, 4-amino- $\alpha$ ( $t$-butylaminomethyl)-3,5-dichlorobenzyl alcohol hydrochloride), a class of therapeutic drugs of $\beta_{2}$-adrenergic agonists, is primarily used in human and veterinary medicine to treat asthma and other pulmonary disorders; however, when orally overdosed, it acts as a repartitioning agent by shifting nutrients from the adipose tissue towards the muscle tissue, and functions as a growth promoter (Ricks et al., 1984). Owing to health concerns about its toxicity reported by numerous researchers (Pulce et al., 1991; Bilbao Garay et al., 1997; Brambilla et al.,

\footnotetext{
¿ Corresponding author

*Project supported by the Department of Science and Technology of Zhejiang Province (No. 2013C02022-2/01), China

(iD ORCID: Sheng-rong SHEN, http://orcid.org/0000-0003-4096-1693

(c) Zhejiang University and Springer-Verlag Berlin Heidelberg 2016
}

1997; Ramos et al., 2003; Barbosa et al., 2005), the use of CLEN has been prohibited in meat-producing animals by many countries, including USA, European Union (EU) member states, China, etc. The symptoms of consumers after ingesting food from this tainted meat were typically described as gross tremors of extremities, tachycardia, nausea, headaches, and dizziness (Barbosa et al., 2005). Of the $\beta_{2}$-agonist sympathomimetic class, CLEN is the only member of drug allowed for the therapeutic use within Europe on animals as a bronchodilator; however, the Food and Drug Administration (FDA) has classified it in Group I drugs with no allowable extra-label uses in any food-producing animal species (Crescenzi et al., 2001). To ensure that meat products are suitable for human consumption, the maximum residue limit (MRL) of CLEN in the livers of cattle and horses proposed by EU is fixed at $0.5 \mu \mathrm{g} / \mathrm{kg}$ (de Wasch et al., 1998). Therefore, a reliable sensitive method is 
required to determine a trace amount of CLEN in meat products below the parts per billion (ppb) levels.

Several techniques have been developed for extracting CLEN from complex matrices. The conventional pre-treatment ones are mainly reliant on liquidliquid extraction (LLE) (Courtheyn et al., 1991; de Wasch et al., 1998; Keskin et al., 1998; Zhang et al., 2003) or solid-phase extraction (SPE) (Horne et al., 1998; Bruins et al., 1999; Li et al., 2010). However, these two classic methods have timeconsuming cleanup steps and require large quantities of toxic organic solvents in order to obtain a homogeneous liquid phase containing an analyte of interest. There are many newly developed pre-treatment methods of $\beta_{2}$-agonists CLEN determination, including molecularly imprinted matrix solid-phase dispersion (MI-MSPD) coupled with high performance liquid chromatography (HPLC) ultraviolet detection (Qiao and Du, 2013), surface molecularly imprinted polymer (MIP) and micro-extraction in a packed syringe (SMIP-MEPS) (Du et al., 2014), MSPD and molecularly imprinted SPE (MISPE) (Huy et al., 2014), and MIP-capped cadmium telluride (CdTe) quantum dots (Qian et al., 2006; Huy et al., 2014; Ying et al., 2014). However, although there are many different procedures each claiming its own benefits, there is still a strong need for a simpler, effective, and efficient method for the extraction of the trace amount of analyte in complex mixtures.

MIPs, possessing the advantages of high selectivity, easy preparation, and high chemical stability, are synthetic polymers which display specific recognition sites for a target analyte (Mahony et al., 2005; Beltran et al., 2010; Prieto et al., 2011; Hiratsuka et al., 2013). MISPE cartridges have been employed to separate pesticides (Muldoon and Stanker, 1997; Zhu et al., 2002; Lv et al., 2007), drugs (Mullett and Lai, 1998; Shi et al., 2007), and illicit food additives (He et al., 2010; Kang et al., 2012) from different biological matrices. The main compositions engaged in the creation of MIPs are the template molecule, the functional group, and the cross-linking agent.

Cyclodextrin was frequently used in the enantiomer separation and drug delivery systems for their unique property to form inclusion compounds with other small molecules (Tsai and Syu, 2005). In recent times, $\beta$-cyclodextrin $(\beta-\mathrm{CD})$ and its derivatives were typically chosen as either a single (Zhong et al., 2001;
Tsai and Syu, 2005; Xu et al., 2008) or a combined use as binary functional monomers (Chen et al., 2007; $\mathrm{Xu}$ et al., 2007; 2010; Kang et al., 2012) to synthesize $\beta$-CD-MIPs; the synthesized MIPs, additionally, have been demonstrated to obtain greater adsorption properties with addition of $\beta-C D$ (Kang et al., 2012).

The objective of the present study was to develop a rapid and sensitive technique to identify a trace amount of CLEN in pig liver samples. The MIP was synthesized using CLEN as the template, and the combined use of allyl bromine- $\beta$-cyclodextrin (allyl$\beta-\mathrm{CD}$ ) and methacrylic acid (MAA), allyl- $\beta-\mathrm{CD}$ and methyl methacrylate (MMA), allyl- $\beta-C D$ and acrylonitrile (AN) as the binary functional monomers; ethylen glycol dimethacrylate (EGDMA) as a crosslinker. An array of assays was performed to evaluate the selective binding efficacy of prepared MIPs, and finally, MIPs were applied to test the spiked liver sample with CLEN constituent to determine the recovery rates through the MISPE procedure.

\section{Materials and methods}

\subsection{Chemicals}

The analytical working standard CLEN (98.5\% ( $\mathrm{v} / \mathrm{v}$, similarly hereinafter)) was ordered from the Laboratory Labor Dr. Ehrenstorfer-Schafers (Augsburg, Germany). Salbutamol, terbutaline sulfate, ambroxol hydrochloride, $\beta$-CD (96\%), allyl bromide (98\%), MAA (99\%), MMA (99\%), EGDMA (98\%), azo- $N, N$-bisisobutyronitrile (AIBN, 99\%), and $N, N$ dimethylformamide (DMF, 99.5\%) were procured from Aladdin Chemistry (Shanghai, China). AN (99\%) and HPLC-grade methanol were purchased from Gracia Chemical Technology (Chengdu, China) and Tianjin Sayfo Technology (Tianjin, China), respectively. Ultra-pure water, used for MIP synthesis and the HPLC mobile phase, was produced from a laboratory water purification system (ultra-pure UF model, Shanghai, China).

$\beta-C D$ and AIBN reagents were re-crystallized from water and methanol, respectively. The selected re-distillated MAA, AN, and MMA functional monomers and already prepared CLEN stock solution $(1 \mathrm{mg} / \mathrm{ml}$ in HPLC-grade methanol) were stored in the refrigerator at $4{ }^{\circ} \mathrm{C}$ prior to their use. All the reagents used in this work were of high-purity grade. 


\subsection{Instruments}

The chromatographic analyses were performed on an Agilent 1200 HPLC system equipped with an ultraviolet-visible (UV-vis) variable wavelength detector (225 nm monitored), binary pump (G1312B), degasser (G1322A), autosampler SL, and temperaturecontrolled compartment (Santa Clara, CA, USA). The reversed-phase column was XB-C18 100A (4.6 mm× $100 \mathrm{~mm}, 1.8 \mu \mathrm{m}$, Phenomenex, USA). The mobile phase composition of acetonitrile and water was blended in a ratio of $4: 1(\mathrm{v} / \mathrm{v})$ with the addition of $0.5 \%(5 \mathrm{~g} / \mathrm{L})$ phosphoric acid $\left(\mathrm{H}_{3} \mathrm{PO}_{4}\right)$. The flow rate was run at $1 \mathrm{ml} / \mathrm{min}$ and the controlled temperature was $30^{\circ} \mathrm{C}$. The injection volume of $10 \mu \mathrm{l}$ and running time of 4 min were observed to result in a sufficiently good response and separation of CLEN compound.

Fourier transform-infrared (FT-IR) spectroscopy (Nicolet, USA) was adopted to characterize the synthetic properties of MIP formations and the scanning electron microscope (SEM; Hitachi, Japan) was used to characterize the properties of synthetic MIP morphology.

\subsection{Preparation of allyl- $\beta-C D$}

The reaction of allyl bromide and $\beta-C D$ was prepared as follows: $20 \mathrm{~g}$ of sodium hydroxide $(\mathrm{NaOH})$ was first dissolved with $20 \mathrm{ml}$ of water in a $100-\mathrm{ml}$ glass beaker. The solution was continually stirred until it was well mixed before $20 \mathrm{~g}$ of $\beta-\mathrm{CD}$ was poured into it. This solution was mechanically stirred in the water bath at $60{ }^{\circ} \mathrm{C}$ for $2 \mathrm{~h}$. Then, $4 \mathrm{mmol}$ allyl bromide was added to the solution and continually stirred under nitrogen gas for $2 \mathrm{~h}$ in the inert atmosphere at $60{ }^{\circ} \mathrm{C}$. The solution was finally transferred back to the water bath for 30 min prior to desiccating in the oven at $60{ }^{\circ} \mathrm{C}$. After a few days, the rigidly dried yield of reaction mixture obtained was crushed and ground into fine powder and washed 5 times with absolute ethanol ( 5 min each time), in order to remove the residues from the resulting product.

\subsection{Synthetic polymerization of MIPs}

MIPs were synthesized according to the previous report (Kang et al., 2012) with some modifications. Allyl- $\beta-C D$ synthetic stock compound $(2.80 \mathrm{~g})$ was first dissolved in $40 \mathrm{ml} \mathrm{DMF}$ for $30 \mathrm{~min}$ prior to adding $2 \mathrm{mmol}$ CLEN to the solution. The reactive solution was processed for $2 \mathrm{~h}$ at a controlled temperature of $60{ }^{\circ} \mathrm{C}$ under continuous magnetic stirring with nitrogen gas purging. A 12-mmol functional monomer (MAA, AN, or MMA) was then added to the solution, allowing $1 \mathrm{~h}$ for reaction. Afterwards, $60 \mathrm{mmol}$ EGDMA was added for another $1 \mathrm{~h}$ reaction, followed by adding $40 \mathrm{mg}$ AIBN as an initiator; the resultant solid-state reaction mixture was obtained after about $30 \mathrm{~min}$ and was then incubated in a water bath at $60{ }^{\circ} \mathrm{C}$ for $24 \mathrm{~h}$. The bulk solid, removed from the thermal bath, was continually desiccated in an oven for $2 \mathrm{~d}$ before being crushed and ground into free-flowing powder through a 400-mesh steel sieve. Fine particles were collected and washed with hot water to minimize possible contaminants. They were subsequently Soxhlet-extracted with methanol and acetic acid (9:1, v/v) until no CLEN was detected by UV-vis spectrophotometry. The MIPs were finally washed with methanol to remove acetic acid residue prior to testing its binding characteristic capabilities.

Non-imprinted polymers (NIPs) were simultaneously prepared under the same conditions except that the CLEN template was removed.

\subsection{Binding assays}

2.5.1 Influence of adsorption solvent on the binding factor

Methanol and water at varying ratios of 10:0, 8:2, $6: 4,5: 5,3: 7,1: 9(\mathrm{v} / \mathrm{v})$ were chosen as a source of solvent to evaluate the binding assays of MIPs and NIPs. Several studies describe MAA monomers as having a great effect on binding adsorption (Shi et al., 2007; Beltran et al., 2010; He et al., 2010; Kang et al., 2012). Thus MAA-linked allyl- $\beta$-CD MIPs (M-MAA) were selected as models amongst the prepared MIPs to evaluate their binding performance for CLEN in different testing solvents. Polymer particles $(20 \mathrm{mg})$ were inoculated for $1 \mathrm{~h}$ in $3 \mathrm{ml}$ of $0.1 \mathrm{mg} / \mathrm{ml} \mathrm{CLEN}$ solution in $10 \mathrm{ml}$ conical flasks by shaking at $140 \mathrm{r} / \mathrm{min}$ at the controlled temperature of $30^{\circ} \mathrm{C}$.

After the defined time of inoculation, the solvent was removed by filtering through $0.22-\mu \mathrm{m}$ filters for HPLC analysis. The percentage of bound substrates to the polymer matrices ( $\left.S_{\text {bound }}\right)$ was calculated from the following equation: $S_{\text {bound }}=$ [(initial amount-free amount after adsorption)/initial amount $] \times 100 \%$. 


\subsubsection{Binding specificity}

All synthetically imprinted and non-imprinted polymers were tested for their rebinding capacities with a target binding molecule of CLEN in solvent media. The amount of template bound to polymers $(Q$, $\mathrm{mg} / \mathrm{g}$ ) was determined by equilibrium binding experiments and calculated according to the following equation (Lv et al., 2007):

$$
Q=V\left(c_{\mathrm{i}}-c_{\mathrm{a}}\right) / m,
$$

where $V(\mathrm{ml})$ is the volume of the solution, $c_{\mathrm{i}}(\mathrm{mg} / \mathrm{ml})$ the initial concentration, $c_{\mathrm{a}}(\mathrm{mg} / \mathrm{ml})$ the free concentration after adsorption, and $m(\mathrm{~g})$ the dried mass of polymers.

The distribution coefficient $\left(K_{\mathrm{d}}, \mathrm{ml} / \mathrm{g}\right)$ of CLEN was used to understand its binding affinity between polymers and the solution. The higher the amount of $K_{\mathrm{d}}$, the greater the role the polymers have played. The following equation for $K_{\mathrm{d}}$ is from a previous study (Zhu et al., 2002):

$$
K_{\mathrm{d}}=Q / c_{\mathrm{a}} .
$$

To understand the significant variation of the amount of uptake between MIPs $\left(Q_{\mathrm{MIP}}\right)$ and NIPs $\left(Q_{\mathrm{NIP}}\right)$, the specific binding capacity $\Delta Q(\mathrm{mg} / \mathrm{g})$ was applied according to

$$
\Delta Q=Q_{\mathrm{MIP}}-Q_{\mathrm{NIP}} .
$$

The molecular imprinting factor (IF) was employed to validate the imprinting result. IF was calculated as follows:

$$
\mathrm{IF}=K_{\mathrm{d}(\mathrm{MIP})} / K_{\mathrm{d}(\mathrm{NIP})},
$$

where $K_{\mathrm{d}(\mathrm{MIP})}$ and $K_{\mathrm{d}(\mathrm{NIP})}$ are the distribution coefficients of MIP and NIP, respectively.

\subsubsection{Binding dynamics and competitiveness}

To study the binding dynamics of each synthetic polymer, $20 \mathrm{mg}$ MIP particles were inoculated for $1 \mathrm{~h}$ in $3 \mathrm{ml}$ of a defined amount of CLEN solution ranging from 0.001 to $0.100 \mathrm{mg} / \mathrm{ml}$ in $10 \mathrm{ml}$ flasks by shaking at $140 \mathrm{r} / \mathrm{min}$ at $30^{\circ} \mathrm{C}$.

A series of structural analogues of CLEN, including salbutamol, terbutaline sulfate, and ambroxol, was tested under the same conditions to characterize the polymers' competitive binding affinity and efficiency, as well as functional recognitions of its structurally related compounds. The concentration of solution was $0.1 \mathrm{mg} / \mathrm{ml}$ in all circumstances. Fig. 1 shows the chemical structures of CLEN and its analogues.<smiles>CC(C)(C)NCC(O)c1cc(Cl)c(N)c(Cl)c1</smiles>

Clenbuterol<smiles>CC(C)(C)NCC(O)c1cc(O)cc(O)c1</smiles>

Terbutaline<smiles>CC(C)(C)NC[C@H](O)c1ccc(O)c(CO)c1</smiles>

Fig. 1 Chemical structures of CLEN and its analogues

\subsubsection{Procedure for preparation of MISPE}

An aliquot $(50 \mathrm{mg}$ ) of MIPs or NIPs was packed into a micro-column (pipet) with a piece of cotton as a stopcock, followed by a thin layer of quartz crystal sand on the top of the polymers. The stock solution of CLEN was prepared in methanol and water $(3: 7, \mathrm{v} / \mathrm{v})$ with the concentrations of 10 and $100 \mu \mathrm{g} / \mathrm{ml}$, respectively. The polymers were pre-conditioned with $3 \mathrm{ml}$ methanol and $3 \mathrm{ml}$ water prior to loading the sample. After conditioning, $1 \mathrm{ml}$ of stock solution containing 10 or $100 \mu \mathrm{g}$ CLEN was loaded into the pipet; a total of $3 \mathrm{ml}$ adsorption solvent was used per sample. It was later washed out with $3 \mathrm{ml}$ hexane in order to displace any non-adsorbed components in the column; hexane has been described as having a good effect on washing for CLEN (Qiao and Du, 2013). A 3-ml elution of methanol containing acetic acid in a ratio of 9:1 (v/v) was run to remove the template material. The eluate was continually collected in a test tube, and dried under nitrogen gas streaming. It was then re-dissolved with $1 \mathrm{ml}$ methanol for HPLC analysis. The elution solvent was eluted through the column with a flow rate of $1 \mathrm{ml} / \mathrm{min}$.

The persistence of CLEN in plasma and urine is reported to be low, but it persists in liver at much higher levels than in other edible tissues and is 
detectable in the liver for up to two weeks after the withdrawal of the drug from an animal's feed (Meyer and Rinke, 1991). Hence, the liver is the tissue of choice for detecting illegal use of CLEN. The liver organ was purchased from local markets and used as our sample. About $3 \mathrm{~g}$ of the ground liver was weighed into a 50-ml polypropylene centrifuge tube and $10 \mathrm{ml}$ water was then added to the sample. The mixture was blended by a vortex agitator for $5 \mathrm{~min}$, then $0.5 \mathrm{~g}$ of sodium chloride $(\mathrm{NaCl})$ and $5 \mathrm{ml}$ hexane were added to the solution, and it was homogenized once again prior to sonicating for $10 \mathrm{~min}$. This solution was separated by centrifugation at $3500 \mathrm{r} / \mathrm{min}$ for $5 \mathrm{~min}$. The collected supernatant was decanted into a test tube, and $3 \mathrm{ml}$ methanol was mixed to precipitate the fat and protein contents and it was subsequently filtered before loading for testing. The recovery experiment $(R)$ was evaluated by spiking blank liver with various concentrations of CLEN standard solutions $(0.005,0.100,1.000$, and $10.000 \mu \mathrm{g} / \mathrm{g}$ liver $)$, and the blank control sample was carried out by the same sample preparation procedure except that CLEN standard solution was removed. The recovery was calculated as follows:

$$
R=C_{\text {mean }} / C_{\text {spiked }} \times 100 \% \text {, }
$$

where $C_{\text {mean }}$ is the mean of the fortified liver concentration, and $C_{\text {spiked }}$ is the spiked concentration.

\section{Results and discussion}

\subsection{Characterization of the synthesized MIPs}

The M-MAA was taken as a model for characterization by FT-IR spectroscopy (Fig. 2). A very sharp peak at $1730.75 \mathrm{~cm}^{-1}$ was a carbonyl group $(\mathrm{C}=\mathrm{O})$ from MAA and EGDMA, $1159.55 \mathrm{~cm}^{-1}$ was $\mathrm{C}-\mathrm{O}$ stretch, and $1636.96 \mathrm{~cm}^{-1}$ indicated the aromatic ring from CLEN compound. A large vibration from around 1450 to $1250 \mathrm{~cm}^{-1}$ was a carbon-carbon single bond $(\mathrm{C}-\mathrm{C})$, confirming that the template and functional monomers were presenting in the polymeric networks (Fig. 2a). Additionally, a very broad band between 3600 and $3000 \mathrm{~cm}^{-1}$ was $\mathrm{O}-\mathrm{H}$ stretching and $2957.06 \mathrm{~cm}^{-1}$ was $\mathrm{C}-\mathrm{H}$ stretch, which is compatible with the $\beta-\mathrm{CD}$ constituent functional structure. For NIPs (Fig. 2b), it was observed that the region and shape of the major bands were similar to those of imprinted polymers.
According to SEM, the imprinted and nonimprinted polymers were remarkably different in texture. The M-MAA looked rough, friable, and porous, while the MAA-linked allyl- $\beta-C D$ NIP (N-MAA) was smooth and compact (Fig. 2c). The irregular, rough, porous MIPs surface is most likely formed by the template removal during Soxhlet apparatus operation creating the particular sites of rebinding cavities.

We chose allyl- $\beta-C D$ and MAA functional monomers as binary functional monomers because the characteristic of allyl- $\beta-C D$ is having hydrophobic inside while having hydrophilic outside the cavity, which enables them to form non-covalent host-guest inclusion complexes with organic and hydrophobic compounds, and MAA has electrostatic attributes that can interact with other guest molecules via hydrogen bonds $\left(\mathrm{H}^{+}-\mathrm{O}^{-}\right)$. Therefore, when we mixed allyl- $\beta-\mathrm{CD}$ and MAA together, the imprinted polymers will increase stronger binding interactions with analyte through hydrophobic effects and hydrogen bonding. In the pre-polymerization process for M-MAA synthesis, when allyl- $\beta-C D$ molecules were mixed with CLEN template in DMF, there is the possibility of aromatic rings of CLEN being either trapped inside or outside the hydrophobic core of ally- $\beta$-CD stereo-shape cavities based on its chemical nature. Whenever the benzene ring is inside, the hydroxyl group $(-\mathrm{OH})$ of CLEN will make a stronger hydrogen bond in the presence of additional MAA monomer. Thus, the allyl- $\beta$-CD and MAA were complementary. The position and mutual conformation of allyl- $\beta-C D$ and MAA were firmly fixed through the crossing-linking agent. This imprinting process is illustrated in Fig. 2d.

\subsection{Binding assays}

3.2.1 Influence of adsorption solvent on the binding factor

As previously mentioned in Section 2.5.1, MAA monomers were demonstrated to have greater yield in binding affinity; therefore, M-MAA and N-MAA were taken as models in this investigation. Fig. 3 shows that the greater the volume of water involved in the adsorption solvent, the greater the effect of the polymers. Hence, an optimal result was obtained when the water content was higher than methanol content. Moreover, there was not a remarkable difference of adsorption capacity between the MIPs and 
(a)

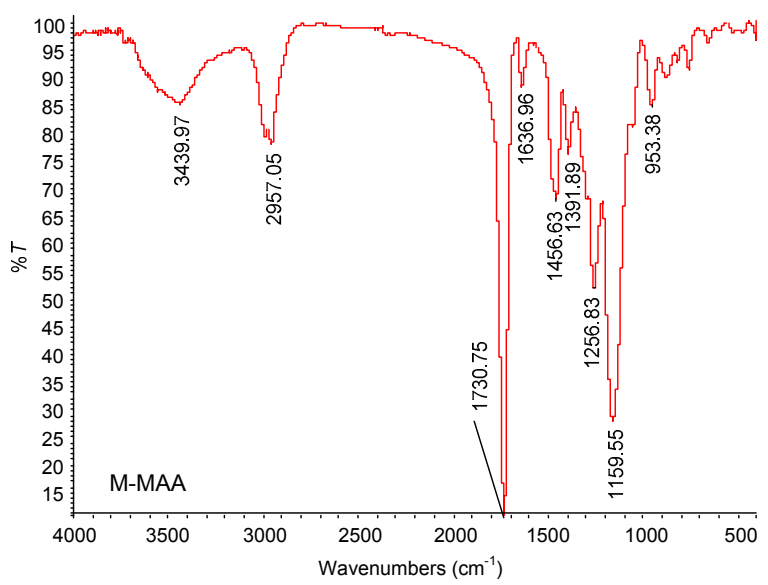

(b)

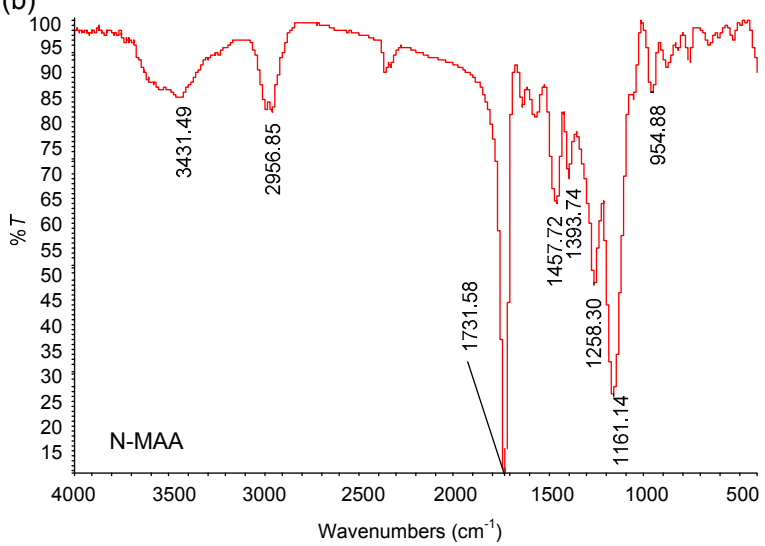

(c)

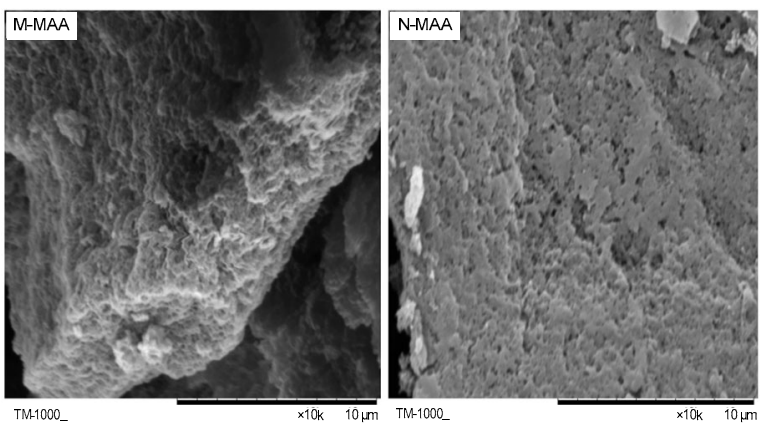

(d)
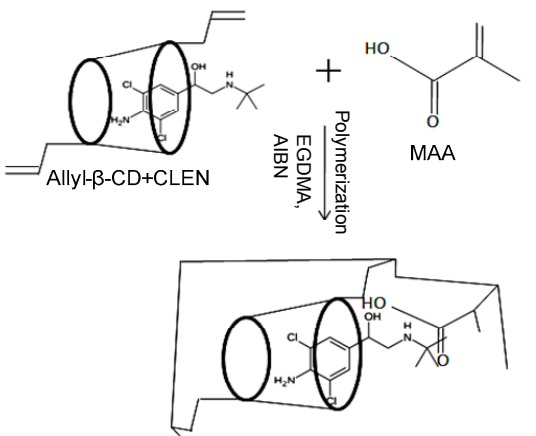

Extraction $\| \widehat{R}$ Rebinding

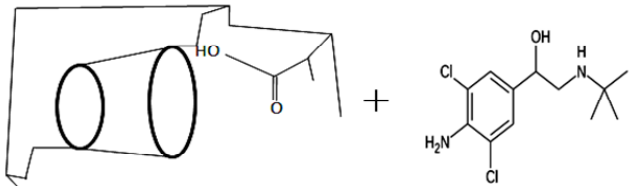

Fig. 2 FT-IR spectra (a, b) and SEM (c) of selected M-MAA and N-MAA, and schematic representation for the preparation (d) of CLEN-imprinted MAA-linked allyl- $\beta$-CD polymer M-MAA: MAA-linked allyl- $\beta$-CD MIPs; N-MAA: MAA-linked allyl- $\beta$-CD NIPs

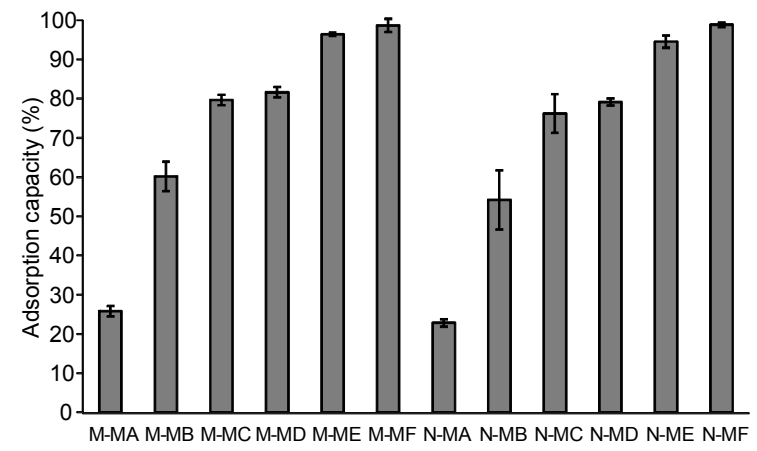

Fig. 3 Influence of solvent on binding factor M: imprinted; N: non-imprinted. MA, MB, MC, MD, ME, and MF denote methanol and water solvent corresponding to a ratio of 10:0, 8:2, 6:4, 5:5, 3:7, and $1: 9(\mathrm{v} / \mathrm{v})$, respectively. Initial content: $0.1 \mathrm{mg} / \mathrm{ml} \mathrm{CLEN}$. Data are expressed as mean \pm standard deviation (SD), $n=3$
NIPs, probably because the analyte concentration employed was relatively low; therefore, there is no doubt that the analyte was readily capable of interacting with polymers in spite of the absence of the imprinting binding sites. In view of this, we eventually decided to use methanol and water $(3: 7, \mathrm{v} / \mathrm{v})$ adsorption solvent for our further work.

\subsubsection{Binding specificity}

Table 1 shows the response of binding performance with various synthesized MIPs. Based on these values, there was a clear indication that polymers made of MAA monomers appeared to be of great functionality in binding forces compared with their counterparts AN and MMA. The average amounts of bound substrates of MAA, AN, and MMA were 14.34, 5.11 , and $4.57 \mathrm{mg} / \mathrm{g}$, respectively, proving that the 
Table 1 Recognition of CLEN uptake on the polymers prepared with different functional monomers

\begin{tabular}{|c|c|c|c|c|c|}
\hline Monomer & $\begin{array}{c}\text { Time } \\
\text { (h) }\end{array}$ & $\begin{array}{c}Q \\
(\mathrm{mg} / \mathrm{g})\end{array}$ & $\begin{array}{c}K_{\mathrm{d}} \\
(\mathrm{ml} / \mathrm{g})\end{array}$ & $\begin{array}{c}\Delta Q \\
(\mathrm{mg} / \mathrm{g})\end{array}$ & IF \\
\hline \multirow[t]{5}{*}{ M-MAA } & 1 & $14.46 \pm 0.44$ & 4034.88 & 0.28 & 1.55 \\
\hline & 3 & $14.38 \pm 1.00$ & 3460.60 & 0.13 & 1.22 \\
\hline & 6 & $14.32 \pm 1.06$ & 3166.23 & 0.27 & 1.42 \\
\hline & 9 & $14.27 \pm 0.45$ & 2941.14 & 0.04 & 1.00 \\
\hline & 12 & $14.27 \pm 2.32$ & 2916.70 & 0.16 & 1.22 \\
\hline \multirow[t]{5}{*}{ N-MAA } & 1 & $14.18 \pm 1.55$ & 2607.41 & 0.69 & 1.26 \\
\hline & 3 & $14.24 \pm 1.18$ & 2827.39 & 1.16 & 1.47 \\
\hline & 6 & $14.06 \pm 1.01$ & 2231.11 & 0.69 & 1.23 \\
\hline & 9 & $14.23 \pm 2.65$ & 2933.07 & 0.29 & 1.09 \\
\hline & 12 & $14.11 \pm 3.12$ & 2381.73 & 2.29 & 2.04 \\
\hline \multirow[t]{5}{*}{ M-AN } & 1 & $4.53 \pm 0.24$ & 64.90 & 0.23 & 1.08 \\
\hline & 3 & $4.78 \pm 0.38$ & 70.21 & 1.42 & 1.62 \\
\hline & 6 & $5.49 \pm 1.22$ & 86.56 & 0.31 & 1.10 \\
\hline & 9 & $4.84 \pm 2.32$ & 71.41 & 1.25 & 1.52 \\
\hline & 12 & $5.94 \pm 2.49$ & 98.22 & 0.83 & 1.37 \\
\hline \multirow[t]{5}{*}{ N-AN } & 1 & $3.84 \pm 1.36$ & 51.58 & & \\
\hline & 3 & $3.62 \pm 2.70$ & 47.71 & & \\
\hline & 6 & $4.80 \pm 1.72$ & 70.50 & & \\
\hline & 9 & $4.55 \pm 0.96$ & 65.36 & & \\
\hline & 12 & $3.64 \pm 0.80$ & 48.14 & & \\
\hline \multirow[t]{5}{*}{ M-MMA } & 1 & $4.29 \pm 0.85$ & 60.04 & & \\
\hline & 3 & $4.79 \pm 2.97$ & 70.30 & & \\
\hline & 6 & $5.13 \pm 1.29$ & 77.86 & & \\
\hline & 9 & $4.78 \pm 2.40$ & 70.05 & & \\
\hline & 12 & $3.87 \pm 2.30$ & 52.19 & & \\
\hline \multirow[t]{5}{*}{ N-MMA } & 1 & $4.06 \pm 1.69$ & 55.58 & & \\
\hline & 3 & $3.37 \pm 0.10$ & 43.48 & & \\
\hline & 6 & $4.81 \pm 2.28$ & 70.84 & & \\
\hline & 9 & $3.52 \pm 1.12$ & 46.03 & & \\
\hline & 12 & $3.05 \pm 1.88$ & 38.22 & & \\
\hline
\end{tabular}

Solvent: methanol/water $(3: 7, \mathrm{v} / \mathrm{v})$; Initial content: $0.1 \mathrm{mg} / \mathrm{ml}$ CLEN. MIP: molecularly imprinted polymer; NIP: non-imprinted polymers; M-MAA: MAA-linked allyl- $\beta$-CD MIPs; N-MAA: MAA-linked allyl- $\beta$-CD NIPs; M-AN: AN-linked allyl- $\beta-C D$ MIPs; N-AN: AN-linked allyl- $\beta$-CD NIPs; M-MMA: MMA-linked allyl- $\beta$-CD MIPs; N-MMA: MMA-linked allyl- $\beta$-CD NIPs. $Q$ values are expressed as mean \pm standard deviation (SD), $n=3$

most effective and efficient monomer in binding with a template was M-MAA. The values of $Q, K_{\mathrm{d}}, \Delta Q$, and IF of the imprinted polymers were all higher than those of the non-imprinted polymers, confirming that the synthetic MIPs were superior to the NIPs. The adsorption value in this investigation was higher than that in the previous report (Du et al., 2014). In addition to this, although varying time was assigned, all polymers were found to become saturated in a 1-h inoculation; therefore, $1 \mathrm{~h}$ was selected as the inoculation time for our further experiments.

\subsubsection{Binding dynamics and competitiveness}

It was observed that MAA functional monomers of synthesized MIPs were very capable of binding with various concentrations of CLEN compared with AN and MMA monomers (Fig. 4a). The recovery rate of M-MAA was approximately $95 \%$ in a $1-\mathrm{h}$ inoculation in a shaker at $140 \mathrm{r} / \mathrm{min}$. Conversely, as a constantly increased concentration of CLEN was added to the adsorption solvents, the effectiveness of binding capabilities of M-AN and M-MMA gradually decreased, indicating that M-AN and M-MMA polymeric networks had poor binding interactions with a template and became saturated when the concentration of CLEN reached $0.01 \mathrm{mg} / \mathrm{ml}$. Thus we can conclude that M-MAA polymers possessed an outstanding functional binding capability. To further differentiate the effect of imprinted and non-imprinted polymers made of the MAA functional group, we next gradually added to the extra initial concentration of CLEN, from 0.1 to $0.4 \mathrm{mg} / \mathrm{ml}$. As shown in Fig. 4a, the result was that the higher the concentration, the lower effect of NIPs on interacting with analyte.

The structurally related molecules of CLEN, including salbutamol, terbutaline sulfate, and ambroxol, were chosen to define the CLEN-imprinted polymers' functional competitiveness. The adsorbed capacity of M-MAA was much greater than those of M-AN and M-MMA. Also, only M-MAA polymers are able to discriminate their structural analogues, probably because $\mathrm{OH}$ residue of MAA is more complementary with $\mathrm{OH}$ residue of the template (Fig. 2d), and thus the hydrogen bonds made of MAA $(\mathrm{H}-\mathrm{O})$ could form a stronger interaction with other molecules than those of AN and MMA. Moreover, Beltran et al. (2010) also reported that amongst functional monomers, MAA has been the most widely used functional monomer for MIP establishment. As a result, the MAA functional monomer was the best choice to construct the strong binding imprinted polymeric networks for the CLEN molecule, whereas AN and MMA did not perform effectively (Fig. 4b). 


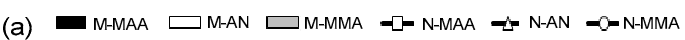
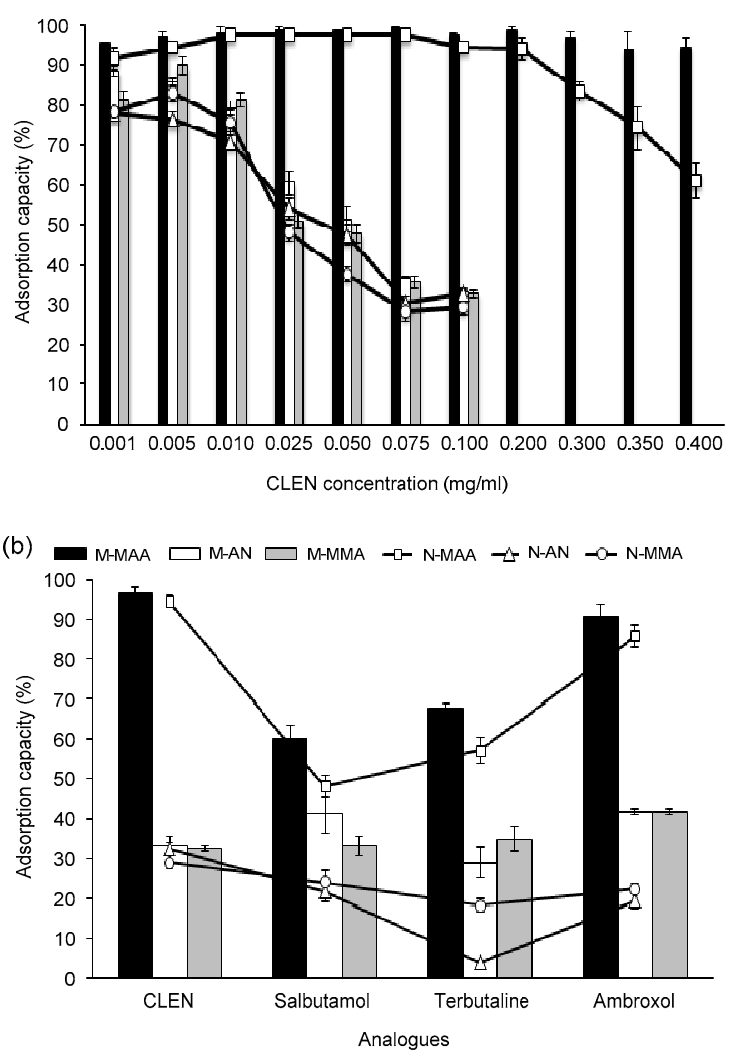

Fig. 4 Binding dynamics of polymers with various concentrations of CLEN (a) and comparison of competitive binding recoveries of template with its analogues (b) Solvent: methanol/water (3:7, v/v); Content: $0.1 \mathrm{mg} / \mathrm{ml}$ CLEN. Data are expressed as mean $\pm \mathrm{SD}, n=3$

\subsubsection{Validation of method via MISPE procedure}

Prior to testing the real sample pre-treatment in a micro-column, a series of experiments was carried out using the procedure described in Section 2.5.4. When the column was injected with $10 \mu \mathrm{g} / \mathrm{ml}$ CLEN, all synthesized polymers performed well in adsorption recovery. This is due to an increase of sorbent particles up to $50 \mathrm{mg}$, which created more available imprinted and non-imprinted poring spaces for the substrate interaction. However, when the amount of substrate was increased to $100 \mu \mathrm{g} / \mathrm{ml}$, only M-MAA polymers retain the same capable function, confirming that the rebinding sites of M-MAA were much stronger and more efficient than those of M-AN and M-MMA. The binding recoveries of M-MAA, $\mathrm{M}-\mathrm{AN}$, and M-MMA for these two different concentrations of CLEN were $95.03 \%, 73.11 \%$, and $66.10 \%$, respectively.
The proposed method, i.e. the MISPE-HPLC method, was validated through specificity, linearity, limit of detection (LOD), limit of quantitation (LOQ), recovery, intra-assay and inter-assay deviation. The specificity of this method was measured by analyzing blank samples. The chromatograms from an HPLC shown in Fig. 5 illustrate that there were no interfering peaks from endogenous compounds at the retention time of CLEN and that the MISPE-HPLC method could enrich CLEN to sufficient purity. The calibration curve of CLEN through HPLC was constructed using the areas of the chromatographic peaks versus the constant concentrations measured at 8 increasing spiked levels of the pig liver sample ranging from 5 to $1000 \mathrm{ng} / \mathrm{g}$ through diluting the stock solution in methanol. Good linearity of CLEN was obtained consistent with a calibration equation of $y=15.52 x+$ $0.739\left(R^{2}=0.998\right)$. The LOD and LOQ, based on signalto-noise ratios of $3: 1$ and $10: 1$, were $0.047 \mu \mathrm{g} / \mathrm{kg}$ and $0.144 \mu \mathrm{g} / \mathrm{kg}$, respectively. Recovery experiments were executed by spiking blank liver with CLEN standard solutions $(0.005,0.100,1.000$, and $10.000 \mu \mathrm{g} / \mathrm{g}$ liver), with five replicates for each concentration. The results from the proposed method showed a high recovery rate of CLEN ranging from $91.03 \%$ to $96.76 \%$ with the relative standard deviation (RSD) values in the range of $2.54 \%-4.45 \%$, which demonstrates that the method was reliable and could be employed for the determination of trace CLEN residues in pig livers. Moreover, the intra-assay precision and accuracy of the method, expressed as the RSD of concentration from known spiked samples on the same day, were $\leq 4.45 \%$, while inter-assay reproducibility in four consecutive days was less than $6.80 \%$ with an average accuracy of approximate $94 \%$.

\subsubsection{Real sample analysis}

To illustrate the suitability and potential of this proposed method, eight pig liver samples were purchased from local markets. In the results, there are no CLEN residues detected in the livers through this method. Therefore, the accuracy of the method was re-evaluated through spiking with two different concentrations ( 1 and $5 \mu \mathrm{g} / \mathrm{g}$ liver) in a real pig sample. The results revealed that the accuracy of recovery was attained about 95\%, reflecting that the proposed method was suitable to be used for the determination of trace CLEN residues in pig livers. 

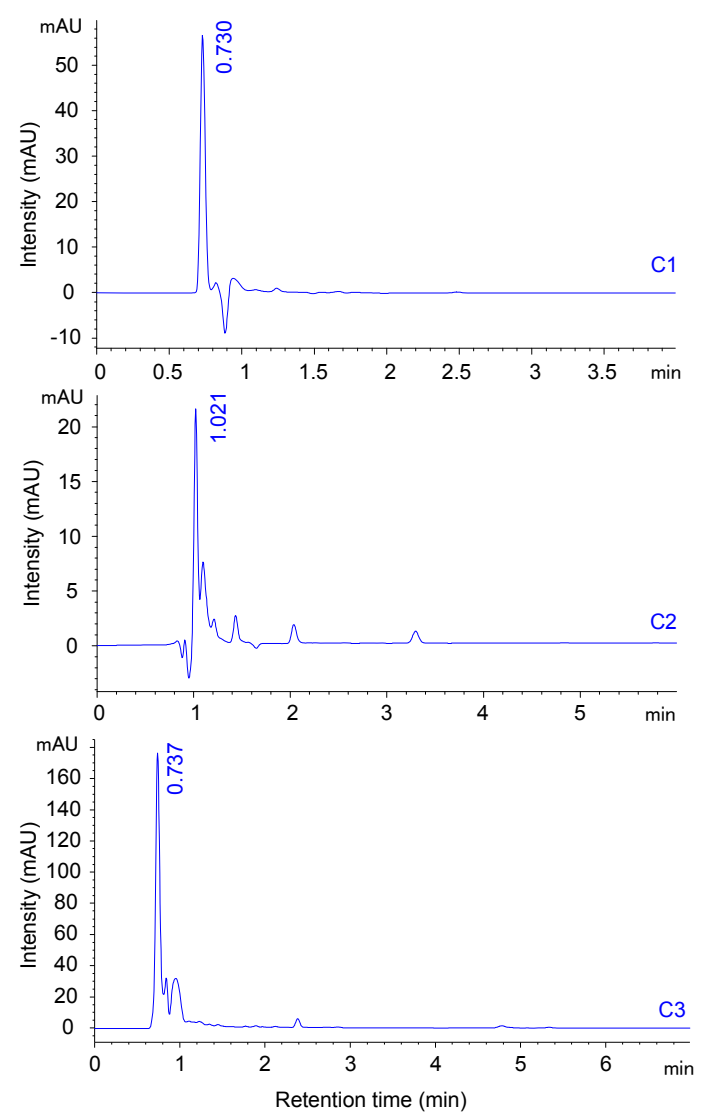

Fig. 5 Chromatograms of HPLC

C1: standard CLEN solution ( $10 \mu \mathrm{g} / \mathrm{ml})$; C2: blank pig sample; C3: eluate of spiked pig sample from M-MAA $(10 \mu \mathrm{g} / \mathrm{g})$

\section{Conclusions}

In this study, a new preparation step of CLENimprinted polymers and extraction method to detect the CLEN residues in pig livers were developed. To our knowledge, this is the first report that has exploited hydrophobic interaction and hydrogen bonding based on allyl- $\beta-C D$ and MAA functional monomers for MIP fabrication for selective recognition of CLEN. We also introduced a new extraction method of CLEN residue from a pig sample. The prepared MISPE procedure is simple and quick; all that is needed are a glass pipette, cotton, and quartz crystal sand. Most importantly, these materials are inexpensive and readily available. Based on the MISPE protocol, only at most $3-5 \mathrm{~min}$ is needed for the whole preparation process. Of the three synthetic polymers, M-MAA was found to be superior to its referent members M-AN and M-MMA, and possessed an effective recognition ability of imprinted polymers. In binding specificity, the average amounts of bound substrates of M-MAA, M-AN, and M-MMA were $14.34,5.11$, and $4.57 \mathrm{mg} / \mathrm{g}$, respectively. M-MAA and N-MAA did not demonstrate substantial differences at low concentrations. However, once the analyte concentration was gradually increased from 0.1 to $0.4 \mathrm{mg} / \mathrm{ml}$, the effect of M-MAA can be differentiated from that of N-MAA. The recovery from a spiked sample was very high, ranging from $91.03 \%$ to $96.76 \%$, with RSD $\leq 4.45 \%$. All in all, this proposed method could be employed for food quality and safety control analysis because of its simplicity, cost-effectiveness, and rapid detection of CLEN residues in pig livers.

\section{Acknowledgements}

We sincerely thank the anonymous reviewers who have taken the time to make comments and suggestions, and also greatly thank Mary JOWETT, a retired science advisor to the Solihull Local Education in the UK and Dr. Willem PARLING, a former voluntary lecturer at Maharishi Vedic University in Cambodia for proofreading this manuscript. We really appreciate their time and contribution to the article.

\section{Compliance with ethics guidelines}

Sovichea LAY, Hai-ning YU, Bao-xiang HU, and Shengrong SHEN declare that they have no conflict of interest.

This article does not contain any studies with human or animal subjects performed by any of the authors.

\section{References}

Barbosa, J., Cruz, C., Martins, J., et al., 2005. Food poisoning by clenbuterol in Portugal. Food Addit. Contam., 22(6): 563-566. http://dx.doi.org/10.1080/02652030500135102

Beltran, A., Borrull, F., Marcé, R.M., et al., 2010. Molecularlyimprinted polymers: useful sorbents for selective extractions. TrAC Trends Anal. Chem., 29(11):1363-1375. http://dx.doi.org/10.1016/j.trac.2010.07.020

Bilbao Garay, J., Hoyo Jiménez, J.E., López Jiménez, M., et al., 1997. Clenbuterol poisoning. Clinical and analytical data on an outbreak in Móstoles, Madrid. Rev. Clin. Esp., 197(2):92-95 (in Spanish).

Brambilla, G., Loizzo, A., Fontana, L., et al., 1997. Food poisoning following consumption of clenbuterol-treated veal in Italy. J. Am. Med. Assoc., 278(8):635-640. http://dx.doi.org/10.1001/jama.1997.03550080045031

Bruins, C.H.P., Jeronimus-Stratingh, C.M., Ensing, K., et al., 1999. On-line coupling of solid-phase extraction with mass spectrometry for the analysis of biological samples: I. Determination of clenbuterol in urine. J. Chromatogr. A, 863(1):115-122. 
http://dx.doi.org/10.1016/S0021-9673(99)00959-0

Chen, C.Z., Chen, C.C., Chung, Y.C., 2007. Removal of phthalate esters by $\alpha$-cyclodextrin-linked chitosan bead. $J$. Bioresource Technol., 98(13):2578-2583. http://dx.doi.org/10.1016/j.biortech.2006.09.009

Courtheyn, D., Desaever, C., Verhe, R., 1991. Highperformance liquid chromatographic determination of clenbuterol and cimaterol using post-column derivatization. J. Chromatogr. B, 564(2):537-549. http://dx.doi.org/10.1016/0378-4347(91)80522-E

Crescenzi, C., Bayoudh, S., Cormack, P.A.G., et al., 2001. Determination of clenbuterol in bovine liver by combining matrix solid-phase dispersion and molecularly imprinted solid-phase extraction followed by liquid chromatography/electrospray ion trap multiple-stage mass spectrometry. Anal. Chem., 73(10):2171-2177. http://dx.doi.org/10.1021/ac0014360

de Wasch, K., de Brabander, H., Courtheyn, D., 1998. LC-MS-MS to detect and identify four beta-agonists and quantify clenbuterol in liver. Analyst, 123:2701-2705. http://dx.doi.org/10.1039/A805039B

Du, W., Lei, C.M., Zhang, S.R., et al., 2014. Determination of clenbuterol from pork samples using surface molecularly imprinted polymers as the selective sorbents for microextraction in packed syringe. J. Pharm. Biomed. Anal., 91:160-168. http://dx.doi.org/10.1016/j.jpba.2013.12.022

He, J., Lv, R., Zhu, J., et al., 2010. Selective solid-phase extraction of dibutyl phthalate from soybean milk using molecular imprinted polymers. Anal. Chim. Acta, 661(2): 215-221. http://dx.doi.org/10.1016/j.aca.2009.12.029

Hiratsuka, Y., Funaya, N., Matsunaga, H., et al., 2013. Preparation of magnetic molecularly imprinted polymers for bisphenol $\mathrm{A}$ and its analogues and their application to the assay of bisphenol A in river water. J. Pharm. Biomed. Anal., 75:180-185. http://dx.doi.org/10.1016/j.jpba.2012.11.030

Horne, E., O'Keeffe, M., Desbrow, C., et al., 1998. A novel sorbent for the determination of clenbuterol in bovine liver. Analyst, 123:2517-2520. http://dx.doi.org/10.1039/A805219K

Huy, B.T., Seo, M.H., Zhang, X.F., et al., 2014. Selective optosensing of clenbuterol and melamine using molecularly imprinted polymer-capped CdTe quantum dots. $B i$ osens. Bioelectron., 57:310-316. http://dx.doi.org/10.1016/j.bios.2014.02.041

Kang, Y.F., Duan, W.P., Li, Y., et al., 2012. Molecularly imprinted polymers of allyl- $\beta$-cyclodextrin and methacrylic acid for the solid-phase extraction of phthalate. Carbohydr. Polym., 88(2):459-464. http://dx.doi.org/10.1016/j.carbpol.2011.12.027

Keskin, S., Özer, D., Temizer, A., 1998. Gas chromatographymass spectrometric analysis of clenbuterol from urine. $J$. Pharm. Biomed. Anal., 18(4-5):639-644. http://dx.doi.org/10.1016/S0731-7085(98)00284-2
Li, C., Wu, Y.L., Yang, T., et al., 2010. Simultaneous determination of clenbuterol, salbutamol and ractopamine in milk by reversed-phase liquid chromatography tandem mass spectrometry with isotope dilution. J. Chromatogr. $A$, 1217(5): 7873-7877. http://dx.doi.org/10.1016/j.chroma.2010.10.055

Lv, Y., Lin, Z., Feng, W., et al., 2007. Selective recognition and large enrichment of dimethoate from tea leaves by molecularly imprinted polymers. Biochem. Eng. J., 36(3): 221-229. http://dx.doi.org/10.1016/j.bej.2007.02.023

Mahony, J.O., Nolan, K., Smyth, M.R., et al., 2005. Molecularly imprinted polymers - potential and challenges in analytical chemistry. Anal. Chim. Acta, 534(1):31-39. http://dx.doi.org/10.1016/j.aca.2004.07.043

Meyer, H.H., Rinke, L.M., 1991. The pharmacokinetics and residues of clenbuterol in veal calves. J. Anim. Sci., 69(11):4538-4544.

Muldoon, M.T., Stanker, L.H., 1997. Molecularly imprinted solid phase extraction of atrazine from beef liver extracts. Anal. Chem., 69(5):803-808. http://dx.doi.org/10.1021/ac9604649

Mullett, W.M., Lai, E.P.C., 1998. Determination of theophylline in serum by molecularly imprinted solid-phase extraction with pulsed elution. Anal. Chem., 70(17): 3636-3641. http://dx.doi.org/10.1021/ac980264s

Prieto, A., Schrader, S., Bauer, C., et al., 2011. Synthesis of a molecularly imprinted polymer and its application for microextraction by packed sorbent for the determination of fluoroquinolone related compounds in water. Anal. Chim. Acta, 685(2):146-152. http://dx.doi.org/10.1016/j.aca.2010.11.038

Pulce, C., Lamaison, D., Keck, G., et al., 1991. Collective human food poisonings by clenbuterol residues in veal liver. Vet. Hum. Toxicol., 33(5):480-481.

Qian, H., Dong, C., Weng, J., et al., 2006. Facile one-pot synthesis of luminescent, water-soluble, and biocompatible glutathione-coated CdTe nanocrystals. Small, 2(6): 747-751. http://dx.doi.org/10.1002/smll.200500530

Qiao, F.X., Du, J.J., 2013. Rapid screening of clenbuterol hydrochloride in chicken samples by molecularly imprinted matrix solid-phase dispersion coupled with liquid chromatography. J. Chromatogr. B, 923-924:136-140. http://dx.doi.org/10.1016/j.jchromb.2013.02.016

Ramos, F., Cristino, A., Carrola, P., et al., 2003. Clenbuterol food poisoning diagnosis by gas chromatography-mass spectrometric serum analysis. Anal. Chim. Acta, 483(1-2): 207-213. http://dx.doi.org/10.1016/S0003-2670(02)01020-6

Ricks, C.A., Baker, P.K., Dalrymple, R.H., et al., 1984. Use of clenbuterol to alter muscle and fat accretion in swine. Fed. Proc. Soc. Exp. Biol., 43:857.

Shi, X.Z., Wu, A.B., Qu, G.R., et al., 2007. Development and characterisation of molecularly imprinted polymers based 
on methacrylic acid for selective recognition of drugs. Biomaterials, 28(25):3741-3749. http://dx.doi.org/10.1016/j.biomaterials.2007.04.036

Tsai, H.A., Syu, M.J., 2005. Synthesis of creatinine-imprinted $\operatorname{poly}(\beta$-cyclodextrin) for the specific binding of creatinine. Biomaterials, 26(15):2759-2766. http://dx.doi.org/10.1016/j.biomaterials.2004.07.037

Xu, Z.F., Kuang, D.Z., Liu, L., et al., 2007. Selective adsorption of norfloxacin in aqueous media by an imprinted polymer based on hydrophobic and electrostatic interactions. J. Pharm. Biomed. Anal., 45(1):54-61. http://dx.doi.org/10.1016/j.jpba.2007.05.024

$\mathrm{Xu}$, Z.F., Xu, L., Kuang, D.Z., et al., 2008. Exploiting $\beta$-cyclodextrin as functional monomer in molecular imprinting for achieving recognition in aqueous media. Mater. Sci. Eng. C, 28(8):1516-1521. http://dx.doi.org/10.1016/j.msec.2008.04.007

Xu, Z.F., Kuang, D.Z., Feng, Y.L., et al., 2010. Combination of hydrophobic effect and electrostatic interaction in imprinting for achieving efficient recognition in aqueous media. Carbohydr. Polym., 79(3):642-647. http://dx.doi.org/10.1016/j.carbpol.2009.09.010

Ying, S., Cui, S., Wang, W., et al., 2014. Simple and sensitive detection method for diprophylline using glutathionecapped CdTe quantum dots as fluorescence probes. $J$. Lumin., 145:575-581. http://dx.doi.org/10.1016/j.jlumin.2013.08.023

Zhang, X.Z., Gan, Y.R., Zhao, F.N., 2003. Determination of clenbuterol in pig liver by high-performance liquid chromatography with a coulometric electrode array system. Anal. Chim. Acta, 489:95-101. http://dx.doi.org/10.1016/S0003-2670(03)00707-4

Zhong, N., Byun, H.S., Bittman, R., 2001. Hydrophilic cholesterolbinding molecular imprinted polymers. Tetrahedron Lett., 42(10):1839-1841. http://dx.doi.org/10.1016/S0040-4039(01)00045-4
Zhu, Q.Z., Haupt, K., Knopp, D., 2002. Molecularly imprinted polymer for metsulfuron-methyl and its binding characteristics for sulfonylurea herbicides. Anal. Chim. Acta, 468(2):217-227.

http://dx.doi.org/10.1016/S0003-2670(01)01437-4

\section{中文概要}

题 目: 分子印迹聚合物作为吸附剂结合液相色谱法测定 盐酸克仑特罗

目 的：测定猪肝脏中微量盐酸克仑特罗的残留量。

创新点: 开发一种新的瘦肉精检测方法。

方 法: 用 $\beta$-环糊精（ally- $\beta-C D ）$ 和甲基丙烯酸（MAA） 为功能单体制作分子印迹聚合物（MIP），以盐 酸克伦特罗作为模板, 用乙烯乙二醇二甲基丙烯 酸酯 (EGDMA) 作为交联剂。联合使用 ally- $\beta-C D$ 和 MAA 作为二元功能单体, 能合成高质量的盐 酸克伦特罗模板。

结 论: 与丙烯腈制作的 MIP (M-AN) 和甲基丙烯酸甲 酯制作的 MIP (M-MMA) 相比, MAA 制作的 MIP 聚合物（M-MAA）被证明具有更好的选择 性萃取能力, 被用来进行分子印记固相萃取猪肝 中残留物。研究结果发现, 其回收率高 ( 91.03\% 96.76\%)，且相对标准偏差低 $(\mathrm{RSD} \leq 4.45 \%)$ 。因此, 这种方法可以用于食品 质量和安全的分析, 具有简单、成本低廉的特点, 能够快速检测猪肝中的瘦肉精残留量。

关键词: 分子印迹聚合物; 分子印迹固相萃取; 盐酸克仑 特罗; $\beta$-环糊精 